\title{
Predictors of Irregular International Migration among Youth in Jimma Zone, South West Ethiopia
}

\begin{abstract}
Ashenafi Woldemichael ${ }^{*}$ and Melese Getu ${ }^{\dagger}$
Abstract

This article deals with irregular international migration among the youth in southwest Ethiopia, which is one of the major issues that grabbed the attention of the international community in recent years. The article draws on a study which aimed at determining major predictors of irregular migration intention among youth in Jimma Zone, Southwest Ethiopia. Irregular migration and human trafficking are serious challenges that people face in Ethiopia in general and in Jimma Zone in particular. Concurrent cross-sectional mixed method study design was deployed, and a total of 347 respondents participated in a quantitative survey and 33 and 6 took part in five Focus Group Discussions and in-depth interviews respectively. The study was conducted in three selected woredas/districts of Jimma Zone between March and April 2018. Variables such as age, political unrest, unreliable information from social media, social networks, the desire for life enhancement, and readiness for taking risk are found to be good predictors or reasons of irregular migration. Age has strong negative correlation $(r=-0.73)$ with irregular migration intention. Personal readiness has very strong $(r=0.96)$ and positive correlation with irregular migration intention. In conclusion, youth in particular and community in general in Jimma Zone favor irregular migration to home situation and prefer to try out other life as livelihood strategy.
\end{abstract}

Keywords: Jimma, irregular migration, predictor

DOI: https://dx.doi.org/10.1314/ejossah.v16i1.2

\footnotetext{
${ }^{*}$ Lecturer, School of Social Work, The College of Social Sciences and Humanities, Jimma University, Email: ashumikael@yahoo.com, Tel.: +251911386863, P.O. Box: 378/ Jimma

${ }^{+}$Corresponding author: Assistant Professor, School of Social Work, College of Social Sciences, Addis Ababa University, Email: melese88@yahoo.co.uk, Tel.: +251911409183, P.O. Box: 1176/Addis Ababa
} 


\section{Introduction}

Irregular migration, which is also called 'illegal' migration, refers to crossing international boundary without having or getting legal authorization from the destination state (International Council on Human Rights Policy, 2010; Kostas, 2017). Recently, the life of Ethiopians, their economic basis and country image is affected by irregular migration at higher level (Emebet, 2002). It seems that migration could benefit just like trade for both sending and receiving countries if it happens in legal means (Fernadeze, 2013). Migration that takes place in a legal way can be reasonable for both sending and receiving communities but the irregular migration puts burden on sending and receiving communities in many different ways.

The geostrategic location of Ethiopia makes it a source, transit and destination of migrants, mostly within East Africa but also to the Middle East (Horwood, 2009). Ethiopians have been migrating to the gulf countries in large numbers in recent years. Even with the current returnee migrant crisis mainly from Saudi Arabia with limited or without any benefit such as personal saving from work but with stories of various types of abuses and disregard, it is of great interest as to why the youth desire to take up irregular migration (even opt for remigration) as a means of coming out of poverty (UN, 2012; IOM, 2011). According to Food and Agriculture Organization (FAO) (2016), despite their past negative experiences, among the returnee migrants of Ethiopia and Somalia from the Saudi Arabia, not less than 50\% have a plan to consider re-migration as livelihood strategy (Fasil, 2014). Various writers in social and behavioral sciences have come up with findings in their study regarding different aspects of the causes of migration but not much has been found with regard to the why of irregular international migration. Moreover, the latter has not received the attention it deserves to date. Mohammed (2016), International Organization for Migration (IOM) (2011) and Muniz (2010) conducted studies on irregular migration where migration burden is high in Ethiopia and other African countries at different times but there is paucity of information as to what engenders youth to migrate in an irregular way. South-west part of Ethiopia provides quite a lot of job opportunities for youth coming from different parts of the country on seasonal basis as it has big coffee and tea plantations. Jimma Zone is known for its suitability for coffee production (Jimma Zone, unpublished report, 2015). Mohammed (2016) calls for the importance of undertaking further research for the purpose of understanding the possible predictors that would help practitioners and policy makers to effectively respond to the problem in question in a tailored manner. Uncovering the when and how of irregular migration and circumstances influencing the timing 
of potential migrants' departure is timely. Currently, issues of irregular migration have caught the attention of the international community tremendously as its consequences are visible in both countries of origin and destinations. Even though, many national and international actors have been doing their best to respond to the root causes of irregular migration, the outcome is not yet satisfactory (Fasil, 2014). Irregular migration has various social impacts on the destination countries as it imposes integration challenge in all areas of social life.

It is, therefore, worth to assess predictors and prospects of migration for the coming years ahead as Africa in general and Ethiopia in particular happens to exhibit possible socio-political instability which in turn affects the youth settlement and their confidence to invest their future in their locality. However, only few studies have been undertaken on determinants of migration in Ethiopia. Furthermore, there are limited numbers of research conducted specifically on assessing predictors of irregular migration in the Ethiopian context in general and in the context of Jimma Zone in particular. Thus, there is a lack of adequate understanding of irregular migration processes other than the limited appreciation of the issues using the traditional push-pull model. Although socio-cultural and economic conditions vary from place to place, there is lack of information regarding the youth intentions to migrate irregularly from Jimma Zone to the Middle East and other western countries (Gudina \& Tariku, 2014). Ethiopia is challenged by different migration patterns and dynamics, which have significant political and socio-political consequences for the country (Belaynesh \& Sagar, 2016). In this regard, irregular migration among the youth in Jimma Zone is ubiquitous, yet there is a meager literature on this theme under consideration.

Moreover, to the knowledge of the authors, most of the literature on migration in Ethiopia tends to focus on explaining and describing the issues under review but very few or none of them had prediction as their main goal. Thus, a study from which this article draws on was designed and executed with the aim of predicting the prospect of irregular migration and thereby partially fill in the gap in the literature under consideration.

\section{Research context}

This study, on which this article draws on, was carried out in Jimma Zone which is one of the 21 Zones in Oromiya region - a region endowed with natural resources. Jimma Zone is located $350 \mathrm{kms}$ to south-west of Addis Ababa. Jimma Zone has a total surface area of $19506.24 \mathrm{~km}^{2}$ all of which are under land body. The zone constitutes nearly $5.4 \%$ of the regional total surface area. The total population of Jimma Administrative Zone was estimated at 2,622,847 in 2009 (CSA, 2010). 
The study used a concurrent cross-sectional mixed method design. With a cross-sectional survey design, the tools employed include a structured questionnaire, interview and focus group discussion guides. Therefore, integrating qualitative and quantitative methods makes it appropriate to handle the multiple dimensions of migration (Bryman, 2004). The study population for this research was youth, aged between 15 and 29, who are aspiring migrants. Both random and purposive sampling techniques were employed to recruit study participants in the quantitative survey and qualitative methods respectively. A multi stage stratified random sampling technique was used to assure the representativeness of the study population. Purposive sampling and snowball approach were used for recruiting indepth interview and focus group discussion participants.

A structured questionnaire was adapted from a study conducted in Bangladesh on attitudinal predictors of potential illegal cross border migration (Ommundsen et al., 2010). A total of 31 items were prepared which assessed intention of potential irregular migrants on a Likert Scale of five points: strongly disagree, disagree, neutral, agree and strongly agree.

The language and items in the data collection tool were evaluated by peer researchers to ensure their appropriateness for the Ethiopian context. A set of questions were also added to the questionnaire to generate data on the basic sociodemographic characteristics of study participants. Both structured and unstructured questions were included to assess variables such as livelihood, achievement on national examination, income and family background.

The survey questionnaire was administered to assess and determine predictors of irregular migrants from the study participants while in-depth interviews and FGD guides were used to generate data on understanding predictors of irregular migration. Moreover, secondary sources were reviewed from available literature on migration trend as well as from irregular immigration management and irregular migration practices in the Ethiopian context in general and southwest part of Ethiopia in particular. The structured questionnaire was first prepared in English and then translated into Afaan Oromo language which is the first language of the study participants.

Data quality for both qualitative and quantitative was ensured at different stages. The quality of qualitative data was ensured during instrument preparation as it was evaluated by peer researchers. Whereas, quality for the quantitative data was insured by double entry, peer review, and pilot test before actual data collection. Validity and reliability of the data were ensured right after pilot test by such measures as rephrasing some questions and simplifying and replacing some of the items with expressions familiar to Jimma Zone Afaan Oromo speakers. In 
addition to the pilot test, peer evaluation of items was also used as a mechanism to ensure validity and reliability for the survey items.

The different dimensions of irregular migration intention were measured using the following seven set of factors. The first factor composed of four items measures issues associated with individual readiness, evaluation of individual norms and intentions. The second factor consists of six items and helps to measure life improvement issues. The third one has seven items which measures judgmental assessment of the potential migrants. The fourth factor consists of four items and measures potential migrants' preparedness to take risks; while the fifth factor consisting of three items and assesses feelings of failure in one's place of origin. The sixth factor is composed of four items, which measure the issue of rights to immigration. Finally, the seventh factor has three items designed to measure potential migrants' benefits and expectations from migration. For each one of the above-mentioned factor cutoff point and interpretations were done. Consequently, the total number of items multiplied by the neutral value was taken as cutoff point for all of the seven factors.

Data analysis for both qualitative and quantitative followed different strategies depending on the nature of data collected. With regard to qualitative data analysis, initial work dwelt on transcribing in-depth interviews and FGD, typing up field notes, sorting and arranging the data into different types depending on the sources of information. The main analysis for qualitative data followed thematic classification of the information and then triangulating with quantitative findings.

Quantitative data were analyzed using both descriptive and inferential statistics. Both dependent and independent variables were described in percentages, frequencies, mean and standard deviation and presented in tabular forms. Independent t- test was done to assess association of dependent variable (irregular migration) with independent variables, and finally utilized linear regression analysis to identify best predictor of irregular migration among the independent variables.

Standardized multiple linear regressions was performed to quantify the effect of independent variables on dependent variable; in this case irregular migration. Finally, independent variables, which have statistically significant associations with the dependent variables ( $\mathrm{P}$ value less than 0.05 ), were entered into final regression model. One way ANOVA was done for categorical independent factors significant in multiple linear regressions like age and educational status. Measures of association were also used for assessing relation between dependent variable and independent variables. 
Ethical approval for conducting the research was obtained from School of Social Work of Addis Ababa University. Study participants took part in the study after securing their willingness and consent. Both written and verbal consent were obtained from the participants. Ethical issues were handled in line with the National Research Ethics Review Guidelines of Ethiopia (MoST, 2014).

\section{Results}

Three hundred forty seven respondents, out of a total sample of 384, filled out the structured questionnaire during the study period, which was conducted from March through April 2018. The data were collected from three woredas namely, Jimma town (30.8\%), Dedo (35.7\%) and Omo Nada (33.4\%).

Table 1: Gender and religion of the respondents' cross-tabulation

\begin{tabular}{|c|c|c|c|c|c|c|c|c|}
\hline \multirow{2}{*}{\multicolumn{3}{|c|}{ Religion }} & \multicolumn{4}{|c|}{ Gender } & \multicolumn{2}{|l|}{ Total } \\
\hline & & & Male & & Female & & & \\
\hline & Frequency & $\%$ & Frequency & $\%$ & Frequency & $\%$ & Frequency & $\%$ \\
\hline Orthodox & 114 & 32.9 & 66 & 19 & 48 & 13.8 & 117 & 32.9 \\
\hline Muslim & 180 & 51.9 & 84 & 24.2 & 96 & 27.7 & 180 & 51.9 \\
\hline Protestant & 38 & 11 & 17 & 4.9 & 21 & 6.1 & 38 & 11 \\
\hline Others & 15 & 4.3 & 8 & 2.3 & 7 & 2 & 15 & 4.3 \\
\hline Total & 347 & 100 & 175 & 50.4 & 172 & 49.6 & 347 & 100 \\
\hline
\end{tabular}

As can be seen from Table 1 above 175 males (50.4\%) and 172 females $(49.6 \%)$ took part in the study from three of the woredas found in nine kebeles of Jimma zone. In terms of religion, the majority of the respondents are Muslims $(51.9 \%)$ followed by Orthodox $(32.9 \%)$ and protestant (11\%). The study found that illegal migration is slightly higher for singles (Mean $=99.6 \&$ $\mathrm{SD}=7.9$ ) followed by divorced respondents (Mean $=96.07 \& \mathrm{SD}=$ 7.1). This might be related with the minimal responsibility of being single and divorced individuals might have in households. In this connection Mohammed's (2016) study conducted in South Wollo has also found a similar result. However, in this study Muslims have slightly higher irregular migration intention (mean $=99.68 \& \mathrm{SD}=7.3$ ) followed by Orthodox Christians $($ Mean $=99.2 \& \mathrm{SD}=7.9)$. We believe that this might have to do with the prevailing information sharing habits among the general population and main stream religions in Ethiopia.This finding is also incongruent with two studies 
conducted in northeastern Ethiopia namely, Raya and South Wollo by Chekol (2017) and Mohammed (2016) respectively.

Table 2: Age of respondents by highest level of education cross-tabulation

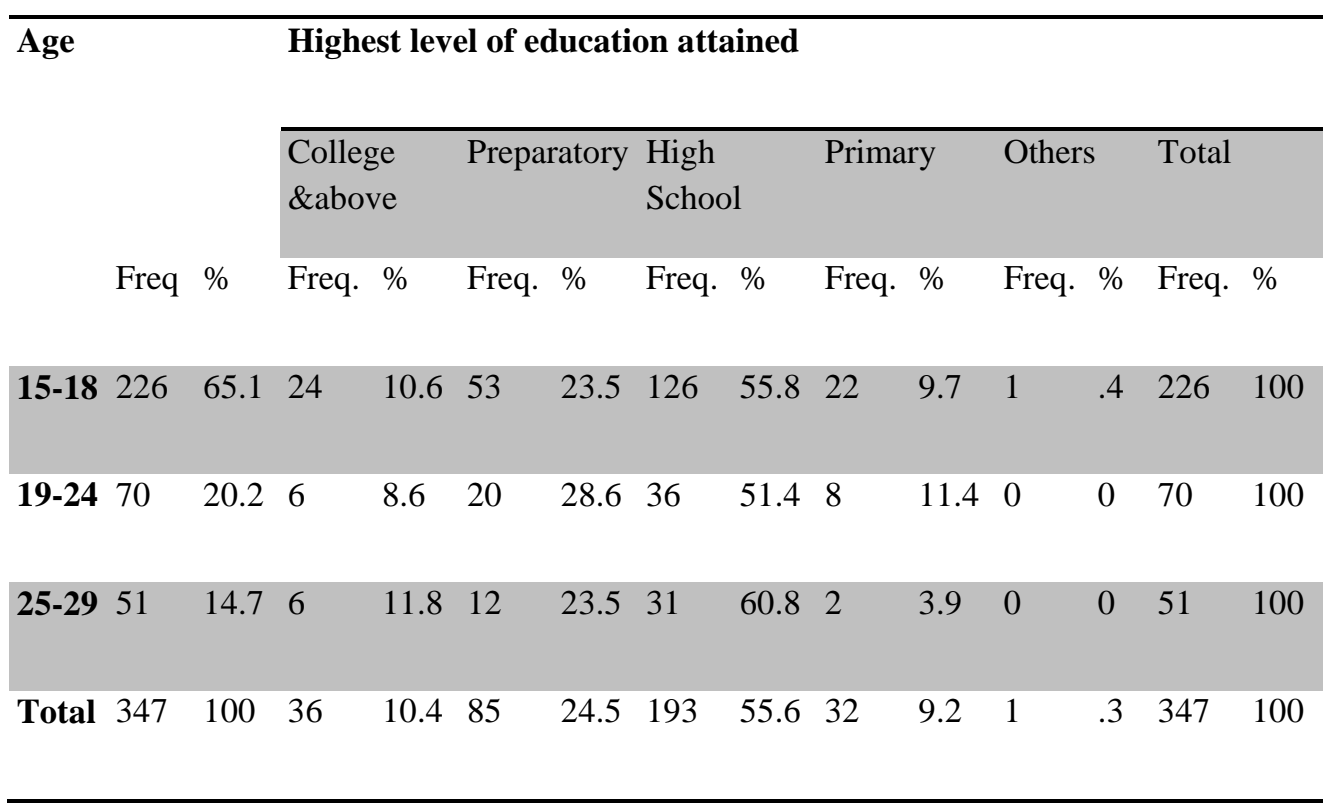

Table 2 above shows that the majority $(65.1 \%)$ of the respondents are found in the age range of 15-18 followed by age range of 19-24 which accounts for $20.2 \%$ of the total. This is the case as the target population of the study was defined to be in the age bracket of 15-29 following the inclusion criteria and the definition of 'youth' as per the National Youth Policy of Ethiopia (2004). Mean age of the respondents was found to be 18.8 years with standard deviation of 3 (Mean=18.8 and $\mathrm{SD}=3$ ).

\section{Factors affecting irregular migration: Education and income}

Education and income are important variables linked with irregular migration both of which are assessed in the context of Jimma Zone. When we look into the level of education of the respondents, the majority of them $(55.6 \%)$ reported that they have graduated from high school followed by those who have completed college preparatory school which accounts for $24.5 \%$ of the total. This 
Ashenafi Woldemichael and Melese Getu

shows that most of the youth in Jimma Zone tend to take their schooling up to high school with great commitment and start to think about other life opportunities including out migration afterwards. In a similar vein, while discussing about the youth in Jimma Zone, one of the experts from Youth and Sports Department of Jimma Zone reported that young people's motive for completing grade ten is related with the intention of trying out different life journeys. This finding is in line with the community expectations of youth. This is also affirmed by an interviewee from Jimma town when he states that: "Timihirt eske 10 kalaleke menja fikad enkuan mawutat ayichalim" (Literally translated as "If one has not completed grade $10 \mathrm{~s} /$ he cannot even obtain a driving license").

Table 3: Frequency distribution of the livelihood of respondents

\begin{tabular}{llll}
\hline Ser.no & Livelihood types & Frequency & Percentage \\
\hline $\mathbf{1}$ & Farming & 167 & 48.1 \\
$\mathbf{2}$ & Formal Employment & 6 & 1.7 \\
$\mathbf{3}$ & Trade & 130 & 37.5 \\
$\mathbf{4}$ & No clear livelihood & 10 & 2.9 \\
$\mathbf{5}$ & Others & 34 & 9.8 \\
$\mathbf{6}$ & Total & 347 & 100 \\
\hline
\end{tabular}

In terms of livelihood from a total of 347 study participants, who responded to this particular variable, the majority $(48.1 \%)$ reported that farming is their main means of livelihood followed by those $(37.5 \%)$ who reported to have depended on trade for their existence. From the above table, we can see that very few of them make a living through formal employment whether as civil servant employed by the government or other organizations. Findings from a research conducted by Tariku and Gudina (2014), on human trafficking, also showed that the reasons for the wide spread practice of trafficking are due to unemployment or availability of limited local opportunities. Poor living conditions, slow progression of income and minimal improvement in quality of life contributed for the problem of human trafficking in Jimma Zone. The above mentioned finding is similar to that of the study on predictors of irregular migration which reveals that there is high likelihood for considering irregular migration as a means of securing a better livelihood among people with low level of income and those who tend to have lost hope in the possibility of improving the standard of their life.

The majority of the respondents $(86.5 \%)$ are found in an income range of 300 to 1000 ETB per month followed by those (8.9\%) who have a monthly income 
range of 1000 to 2000 . The average income of the respondents is found to be 917 ETB with standard deviation ( $\mathrm{SD}=689$ ).

In this regard, a study participant named Abinet (Name changed) has the following to say during a focus group discussion session held with female participants in Jimma town:

Even though you work in Jimma, it is very difficult to meet the demands of life. The return from what you do as a small business owner or government employee does not make you happy. I once tried to set up a small shop of my own but the taxation, I was expected to pay, was so high that I gave it up; and now I am contemplating to try to migrate to Dubai as I heard that there is an opportunity to work and lead a better life there.

A 22-year old male in-depth interview participant from Dedow woreda offered the following answer when he was asked about the source of his family income:

It is difficult to say this or that is our source of income as we always seek for opportunities that might give short-term solution for solving family economic concerns we have. These days there is a big construction underway in our woreda in which many farmers including my father go sometimes to work and make money and other times he is involved in petty trade during the agricultural slack period while waiting for the cereal crops harvest.

FGD participants also acknowledged the fact that the months from April to June are the most difficult period to feed themselves for most households in Jimma Zone. The coping mechanisms adopted by respondents vary from place to place and from one household to another but the most commonly cited one being moving out from one's place of origin in search of causal jobs like working as a daily labourer in semi-urban areas on seasonal basis and get back home when the harvest is ready.

We cannot sit down and die of hunger waiting for the harvest season to come. So what we do is try everything possible to feed and maintain the family. We make sure that all members of the family survive the hardship with good management of resources. The 
interesting thing about the low income related experience of many households in our area is that it recurs almost every year but we tend to forget about it during the onset of the harvest season. It is in part associated with our mismanagement practice that makes our life miserable and results in food insecurity and uncertainty. I know that some households sold their property like land to urban dwellers and now they work as laborers for the person they sold the land.

Table 4: Pearson correlation for income and irregular migration (overall)

\begin{tabular}{|c|c|c|c|}
\hline \multicolumn{4}{|c|}{ Correlations } \\
\hline \multirow{4}{*}{$\begin{array}{c}\text { Irregular } \\
\text { migration } \\
\text { intention }\end{array}$} & $\begin{array}{c}\text { Pearson } \\
\text { Correlation } \\
\text { migration } \\
\text { intention }\end{array}$ & $\begin{array}{c}\text { average income of } \\
\text { participant per } \\
\text { month }\end{array}$ \\
\cline { 2 - 4 } & Sig. (2-tailed) & 1 & .027 \\
\cline { 2 - 4 } & $\mathrm{N}$ & 346 & .615 \\
\hline $\begin{array}{c}\text { Average income } \\
\text { of participant per } \\
\text { month }\end{array}$ & Correlation & .027 & 346 \\
\cline { 2 - 4 } & Sig. (2-tailed) & .615 & 1 \\
\cline { 2 - 4 } & $\mathrm{N}$ & 346 & 347 \\
\hline
\end{tabular}

As can be observed from Table 4 above, the Pearson correlation shows weak association $(\mathrm{r}=0.026)$ between income and illegal migration intention which means decrease in income has lower likelihood of having relationship with irregular migration intention. This might be related with current job opportunities and business schemes growing in the country which encourages the youth to engage in one's own business when they have higher income than considering to take irregular migration. These findings differ from other studies conducted in 36 
Ethiopia about migration and its correlations with income. This is also contrary to the assumption that people who migrate are those who are able to pay for their travel. This study reveals that as income increases migration intention decreases. However, the qualitative finding is not in support of the quantitative finding. Both individual depth interviewees and FGD participants maintain that they would choose to leave the country if they have the financial capacity to afford for processing their travel as they see better future by going to other developed countries. The possible reasons for the difference in the qualitative and quantitative findings might be attributed to exposure of potential migrants to few successful stories of migrants in their respective locality. In our study most of the FGD and indepth interview participants were from households where someone was abroad or returnee as we intended to have deeper understanding of the subject by approaching those with some level of familiarity with international migration issues.

\section{Irregular migration and decision-making}

Attempt was made to identify factors which influence the process of migration decision-making of potential migrants. Respondents were asked if they have siblings to support or not. Most of them (84.1\%) reported that they have siblings while the remaining $(15.9 \%)$ reported to have no siblings. The decision to migrate is found to be influenced by the presence of siblings as many potential migrants take this issue into consideration.

Table 5: Respondents social network, decision-making and prospect of irregular migration

\begin{tabular}{lllllll}
\hline $\begin{array}{l}\text { Ser. No Who influenced your } \\
\text { decision? }\end{array}$ & \multicolumn{2}{c}{ Distribution } & $\begin{array}{l}\text { Who would you } \\
\text { consult? }\end{array}$ & \multicolumn{2}{l}{ Distribution } \\
\cline { 6 - 7 } & Freq. $\%$ & & Freq. & $\%$ \\
1 & Father & 114 & 32.9 & Father & 95 & 27.3 \\
2 & Mother & 198 & 57.1 & Mother & 207 & 59.7 \\
3 & Elder sibling & 11 & 3.2 & Elder sibling & 15 & 4.3 \\
4 & Others & 24 & 6.9 & Others & 30 & 8.7 \\
5 & Total & 347 & 100 & Total & 347 & 100 \\
\hline
\end{tabular}


The result has also shown that most of the respondents (57.1\%) are influenced by their mothers on their decision-making with regard to matters affecting their life. Accordingly, the majority (59.7\%) of them reported that they would consult their mothers more likely than they do their fathers or elder sibling. Next to mothers, respondents reported that they would consult their fathers $(27.3 \%)$ on their migration plan and other life issues. So parents in general and mothers in particular tend to influence youth decision-making as compared to others including elder siblings.

This finding is in agreement with that of Mohammed's (2016) who found that the decision of youth is highly affected by their significant others and these important others are family members mainly mothers and fathers. And this can be explained in association with the local context of child socialization practices in which children spend most of their time with mothers who are often engaged in domestic work and thereby develop very close relationships with their mothers compared with that of their fathers. This survey result is similar with the qualitative finding; in that participants reported that their decision is highly molded and influenced by their parents. In this connection, a 19-year old female in-depth interview participant from Jimma town has this to say:

I cannot do anything without discussing it with my parents as they are the one to whom I will get back if something happens or fails in my life. I have never made any move without consulting them and I will do the same for the future. I specially talk with my mother on my life plan. I remember times in which I discussed with her about my wish to migrate following my failure in grade ten national exams.

The FGDs conducted with returnee migrants in Jimma town have clearly shown that they considered migration as the highest form of bravery and this is in agreement with the survey findings. It is those persons with courage who decide and make plan for trying something new. One of the FGD participants from Jimma shared her experience as follows:

I was discouraged by my friends and family before I left for Addis Ababa where I stayed for few months until I get things clear as to which route to take. Then I learned that it is better to do something different and see what happens than doing what everybody does here. I always wished to be like returnee youths from aboard and yearned to get the respect they got from the community. If you happen to be 
someone who returned from abroad people will highly welcome you and they are likely to highly consider you as someone who knows many things. It is partly this and partly the challenges you face in life in my place of origin which made me feel hopeless and beyond my control that encouraged me to become one of the migrants.

\section{Factors associated with irregular international migration intention}

The mean intention to migrate in to another country in an illegal way was found to be 3.9 on a scale of 1 (no intention at all) to 5 (very strong intention). Zero order variable correlation is presented in Table 6 below.

Table 6: Correlation among variables

\begin{tabular}{|c|c|c|c|c|c|c|c|c|c|c|}
\hline Variable & $\mathrm{G}$ & A & 1 & 2 & 3 & 4 & 5 & 6 & 7 & 8 \\
\hline Gender (G) & 1 & & & & & & & & & \\
\hline $\operatorname{Age}(A)$ & $0.049 *$ & 1 & & & & & & & & \\
\hline $\begin{array}{l}\text { Personal } \\
\text { readiness(1) }\end{array}$ & $-0.11 *$ & -0.02 & 1 & & & & & & & \\
\hline $\begin{array}{l}\text { Personal norms } \\
\text { and evaluation (2) }\end{array}$ & $-0.08 * *$ & -0.08 & 0.41 & 1 & & & & & & \\
\hline Improve life (3) & $-0.12 *$ & $0.06 *$ & 0.96 & $0.37 *$ & 1 & & & & & \\
\hline $\begin{array}{l}\text { Moral } \\
\text { evaluation(4) }\end{array}$ & $-0.23^{*}$ & -0.02 & 0.24 & $0.83 *$ & 0.19 & 1 & & & & \\
\hline Risk taking (5) & $-0.21 * *$ & -0.16 & 0.19 & 0.34 & 0.16 & 0.3 & 1 & & & \\
\hline $\begin{array}{l}\text { Feeling of failure } \\
\text { in own country }(6)\end{array}$ & $-0.01 * *$ & -0.03 & 0.61 & 0.65 & 0.03 & 0.66 & 0.42 & 1 & & \\
\hline $\begin{array}{l}\text { Right to migrate } \\
\text { (7) }\end{array}$ & $-0.21 * *$ & -0.12 & 0.13 & 0.06 & 0.13 & 0.02 & 0.86 & 0.06 & 1 & \\
\hline $\begin{array}{l}\text { Benefit expectancy } \\
\text { (8) }\end{array}$ & $-0.01 * *$ & $-0.23 *$ & 0.05 & 0.6 & 0.03 & 0.61 & 0.39 & 0.95 & $\begin{array}{l}0.0 \\
7\end{array}$ & 1 \\
\hline
\end{tabular}


As we can read from Table 6 above, age has strong negative correlation(r=$0.73)$ with irregular migration intention. This means as age of participants increases, intention for 'illegal' migration decreases. Personal readiness has very strong $(\mathrm{r}=0.96)$ and positive correlation with improving one's life. These two factors highly contribute to irregular migration intention; in that if improving one's own life is high priority for the person in any way, the personal readiness increases and thereby intention for migration in any way including irregular migration gets higher. Right to immigrate has a very strong $(\mathrm{r}=0.86)$ positive correlation with risk taking appetite and they also predict migration intention of youth. If the person thinks that it is his/her right to immigrate abroad in any way, then s/he would take any risk to achieve that and both these factors also show the possibility of individuals to consider irregular migration as a mechanism to get in to the place they think would make their dream come true.

Table 7: Regression analysis for number of siblings and dependent variable

\begin{tabular}{|c|c|c|c|c|c|c|c|c|}
\hline \multicolumn{9}{|c|}{ Coefficients $^{\mathrm{a}}$} \\
\hline \multirow{2}{*}{\multicolumn{2}{|c|}{ Model }} & \multicolumn{2}{|c|}{$\begin{array}{l}\text { Unstandardized } \\
\text { Coefficients }\end{array}$} & \multirow{2}{*}{\begin{tabular}{|c}
$\begin{array}{c}\text { Standardized } \\
\text { Coefficients }\end{array}$ \\
Beta \\
\end{tabular}} & \multirow[t]{2}{*}{$\mathrm{T}$} & \multirow[t]{2}{*}{ Sig. } & \multicolumn{2}{|c|}{$\begin{array}{l}95 \% \text { Confidence } \\
\text { Interval for B }\end{array}$} \\
\hline & & B & Std. Error & & & & $\begin{array}{l}\text { Lower } \\
\text { Bound }\end{array}$ & $\begin{array}{l}\text { Upper } \\
\text { Bound }\end{array}$ \\
\hline \multirow[t]{2}{*}{1} & (Constant & 103.833 & 1.192 & & $\begin{array}{r}87.14 \\
4\end{array}$ & .000 & 101.489 & $\begin{array}{r}106.17 \\
6\end{array}$ \\
\hline & $\begin{array}{l}\text { number } \\
\text { of } \\
\text { siblings }\end{array}$ & -1.574 & .417 & -.200 & -3.778 & .000 & -2.394 & -.754 \\
\hline \multicolumn{4}{|c|}{$\begin{array}{l}\text { a. Dependent Variable: irregular } \\
\text { migration intention }\end{array}$} & & & & & \\
\hline
\end{tabular}

a. Dependent Variable: irregular migration intention

From Table 7 above, we can see that an irregular migration intention is lower for individuals with more than one sibling. As the number of siblings 40 
increases by one, irregular migration intention decreases by 1.574 significant at $\mathrm{p}<.00$.

The regression equation for predicting irregular migration from number of sibling is presented below:

$y=103.833+(-1.54)^{*}$ number of siblings. E.g. if someone has 2 siblings and the other just one. For someone with just one sibling: $y=103.833+(-1.54) * 1=102.2$ which is less than 103.8. In this case, (103.8) is a mean irregular migration intention for those with no sibling at all. For two sibling: $y=103.833+(-$ $1.54) * 2=100.7$ this is still less than both cases above.

When we see this result it may be related with information gained from siblings about the harshness of irregular migration that might contribute to lower irregular migration intention. As we can see from Table 7 above and also presented on the model summary, there is a statistically significant relationship between number of siblings and irregular migration intention.

\section{Discussion}

Migration is a complex phenomenon and a key component of livelihood strategies in rural households, which focus on minimizing risks and diversifying household income as it is also found from this study in Jimma Zone, which is in line with Mohammed's (2016), findings as well. The process of migration starts when individuals decide to leave their country of origin either because their lives are not safe or they seek protection abroad (forced migration), or because they look for better economic opportunities (labor migration). Individuals do not make such decisions alone. In relation to this Ritzer (2011), for example, argues that "an individual's mental state is influenced by his/her social group" The current study on which this article is based reveals that positive desire for life enhancement, high personal readiness, and readiness for taking risk, age, and peer pressure as predictors of irregular migration. Together with the above factors social network plays greater role for irregular migration intention among the youth in Jimma Zone and it is in agreement with what Ritzer (2010) found about the decision of migrants being influenced by their social group.

The results from this investigation have also revealed that poverty, lack of sense of security and limited livelihood opportunities also explained as good predictors of irregular migration to places considered better to get those things missed at place of origin.

Living conditions at home, perception of earning opportunities abroad, and the immigration policies of potential destination countries play a great role in a potential migrant's decision as to whether s/he should consider migrating in 
regular or irregular ways. This finding may reflect an "egocentric" desire to participate in the consumer culture of global north and the Middle East (Friez, 2004). However, it may also indicate that Ethiopians evaluate irregular migration as a strong necessity in order to help their family. Furthermore, it is worth noting that this study also determined that social ties as one of the potential predictors (57.1\%) for considering irregular migration; as parents highly influence the decision of migrants in Jimma Zone.

It is a well-documented fact that migration decision is determined by many factors at individual and societal levels. A better way of conceptualizing the migration decision is through subjective cost-benefits comparison that takes in to account many factors including possible barriers to migration (such as restrictive immigration policy of destination country) and the cost to overcome them (Mbaye, 2013, \& Tim, 2005). Furthermore, the cost-benefit analysis of migration heavily depends on individual and family factors; such as education level achieved, level of parents profession, migration history of family in general and history of mother's migration in particular, language skills, social networks and social and economic prospect in own country or locality. This finding from Jimma is congruent with findings of a research conducted on the attitudes of Sudanese youth towards international migration (Yaseen, 2012).

Likewise, in Jimma Zone, it is not unusual to find more than one child who has been to the Middle East. What is referred to as 'chain migration' where everyone in one's circle follows everyone else in that circle is also common in Jimma Zone. This is in line with Mbaye's (2013) arguments that the presence of family members, close relatives and best friends at destinations helps to predict irregular migration strongly.

\section{Conclusion}

Irregular international migration has been considered as a multi-dimensional phenomenon. In that a range of factors have either facilitated or hindered the occurrence of irregular international migration. This article draws on a study which tried to determine predictors of irregular international migration and factors which influence irregular migration intention in Jimma Zone, South-west Ethiopia. Accordingly, the article revealed that as age increases migration intention reduces. And this might be moderated by a host of factors including exposure to risks of irregular migration, engagement in other livelihoods, shouldering social responsibility, migrants' and their parents level of educational attainment. The migration intention of young men and women with parents with a better level of educational attainment and thereby being employed in the formal sector was found 
to be high compared with those whose parents were less educated and make a living in the informal sector.

Political unrest and the presence of a person in one's social networks in the Middle East were found to be good predictors of irregular migration among youth in Jimma Zone. In other words, the more there is a political unrest and the availability of a relative or a friend in the Middle East the more young men and women tend to out migrate and vice versa. The article has also shown that as income increases the demand for moving out from one's place of origin to other areas in search of better opportunities is positively associated with the intention for irregular migration. Parents in general and mothers in particular are found to have influenced young men and women's decisions on irregular international migration. In terms of places of destination of migrants, most of the young men and women respondents from Jimma Zone reported to have aspired to migrate to the Middle East.

The irregular international migration intention of youth, the subject of consideration of this article, is highly associated with lack of job opportunities in the country and, to a large extent, driven by the search for better money making opportunities abroad. Many actors, including the government, have been dealing with the problem of irregular international migration and its appalling consequences. In this regard, the Ethiopian government might have been doing its best to tackle the problem of irregular international migration through the creation of jobs for the youth. Yet, the problem continued unabated. Thus, the current fragmented approach to address irregular migration in particular and migration in general calls for developing a national migration policy and a comprehensive strategy to deal with the problem of irregular international migration.

\section{Acknowledgement}

Ashenafi would like to thank KAAD Scholarship for granting him the opportunity and for the financial and moral support given to him throughout his course of study. His special thanks also go to Dr. Marko Kuhn KAAD, Head for Africa Department. We also wish to thank all study participants who have given us their time in filling out questionnaires, sitting and responding to interview questions and taking part in FGDs. 
References

Balayneh Genoro Abire, \& Sagar, G. (2016). The determinant factors of illegal migration to South Africa and its impacts on the society in case of Gombora district, Hadiya zone in Ethiopia: A Bayesian approach. Journal of Mathematics, 12(3), 51-65.

Bryman, A. (2004). Social research methods ( $4^{\text {th }}$ ed.). Oxford: Oxford University Press.

Bijack, J. (2006). Forecasting international migration: Selected theories, models, and methods (working paper 4). Warsaw: Central European forum for migration research.

Central Statistical Agency. (2012). Ethiopian welfare monitoring survey 2011 (Summary Report). Addis Ababa: CSA.

Cramer, D. (1998). Fundamental statistics for social research. London. Routledge.

Emebet Kebede. (2002). An assessment of the international labour migration situation, the Case of female labour migrants, Addis Ababa, Ethiopia. Geneva: Gender Promotion Programme International Labour Office.

FAO. (2016). Addressing the root causes of migration and harnessing its potential for development. Rome Retrieved from:

https://knowledge.unccd.int/publications/migration-agriculture-and-ruraldevelopment-addressing-root-causes-migration-and

Fasil Tessema. (2014). Magnitude and pattern of migration: Evidence from Gilgel Gibe health and demographic surveillance system (ISC, 2015 INDEPTH). Jimma University.

FDRE. (2004). National youth policy. Addis Ababa: FDRE Ministry of Youth and Sports.

Fernandez, B. (2013).Traffickers, brokers, employment agents, and social networks: The regulation of intermediaries in the migration of Ethiopian domestic workers to the Middle East. International Migration Review, 47(4), 814-843.

Global Migration Data Analysis Center. (2015). Global migration trends factsheet. Berlin: GMDAC.

Gudina Abashul, \& Carol, A. (2019). The socio-cultural and economic conditions to illegal migration in Omo Nada District, Jimma Zone, Oromia National Regional State, South West Ethiopia. Res., Soc. Dev., 8(7), 1-29.

Haug, S. (2008). Migration networks and migration decision making. Journal of Ethnic and Migration Studies, 34(4), 585-605. 
Horwood, C. (2009). In pursuit of the Southern dream: Victims of necessity, assessment of the irregular movement of men from East Africa and the Horn to South Africa. Geneva: IOM.

International Council on Human Rights Policy. (2010). Irregular migration, migrant smuggling and human rights: Towards coherence. Geneva.

Kostas, S. (2017). Irregular vs. illegal Immigration: Setting the definition. An overview of European practice. Bratislava: Institute of Ethnology, SAS.

Mbaye, M., L. (2013). Barcelona or die: Understanding illegal migration from Senegal (IZA Discussion Paper No. 7728). Germany, Bon.

Mohammed, Y., A. (2016). Cause and consequence of cross border illegal migration from South Wollo, Ethiopia. Arts Social Sciences Journal, 7(2), 120.

MoST. (2014). National research ethics review guidelines. Addis Ababa.

Muniz, O., Li, W., \& Schleicher, Y. (2010). Migration conceptual framework: Why do people move to work in another place or country? USA: AAG Center for Global Geography Education.

Ommundsen, A., Kees,V., Krumov,K., Hristova,P., Ivanova,S., Ivanova, D., \& Larsen,K. (2010). Attitudinal predictors of potential illegal cross-border migration. The Open Social Science Journal, 3, 60-67.

Regional Mixed Migration Secretariat. (2014). Blinded by hopes: attitude, knowledge and practice of Ethiopian migrants. Nairobi: Mixed migration research series.

Ritzer, G. (2005). Sociological theory; ( $7^{\text {th }}$ ed.) New York: McGraw Hill Inc.

Ritzer, G. (2011). Sociological theory ( $8^{\text {th }}$ ed.). New York: McGraw Hill Inc.

Jimma Zone Administration. (2015). Annual report (unpublished). Jimma

IOM. (2010). World Migration 2010. The future of migration: Building capacities for change. Geneva: International Organization for Migration.

Tim, E. (2005). Migration decision making and social networks. EU Marie Curie Excellence grant project.

UN. (2012). The correlation of migration and sustainable development: Seminars on migration and sustainable development. New York: United Nations.

Yaseen, H., S. (2012). The positive and negative impact of remittances on economic growth in MENA countries. The Journal of International Management Studies, 7(1), 7-14. 